\title{
MORPHOMETRICS OF THE LARGEST NEW WORLD MARSUPIALS, OPOSSUMS OF THE GENUS DIDELPHIS (DIDELPHIMORPHIA, DIDELPHIDAE)
}

\author{
Diego Astúa \\ Universidade Federal de Pernambuco, Departamento de Zoologia, Laboratório de Mastozoologia. Av. Prof. \\ Moraes Rego s/n, Cidade Universitária. Recife, PE, Brasil. CEP: 50670-901. E-mail: diegoastua@ufpe.br
}

\begin{abstract}
Opossums of the genus Didelphis include the largest living species of New World marsupials. Although species of the genus have been morphometrically analyzed separately in several studies, size and shape variation within the genus has never been assessed with all species simultaneously. Here I provide the first comprehensive analysis of diversification in size and shape in the cranium and mandible in the living species of Didelphis. I established a set of landmarks to capture the size and shape of the cranium and mandible, using a sample of 344 specimens. I then compared species in size and assessed the major axes of shape variation and differentiation through Principal Components and Canonical Variates analyses of the Procrustes coordinates of these landmarks. Additionally I assessed the effect of size on shape variation by regressing PC and CV scores onto centroid sizes. This analysis shows that almost all species can be distinguished in size, except for two species of white-eared opossums. Shape variation and diversification is also highly driven by size effects, as the most distinctive species in size, D. virginiana, is also the most distinctive species in shape, due to allometric shape changes. Major axes of shape variation are correlated with size, indicating that size plays a major role in the morphological diversification of the genus Didelphis, and these correlations are shared and conserved across species.
\end{abstract}

Keywords: Didelphis; Didelphidae; morphological evolution; morphometrics; shape; size.

\section{INTRODUCTION}

Opossums of the genus Didelphis Linnaeus, 1758 are present in the New World fauna since the late Miocene (Cozzuol et al. 2006), and include the largest living species of New World marsupials. Species of this genus range in head and body length and weight from ca. $300 \mathrm{~mm}$ and $500 \mathrm{~g}$ in the smallest adults of Didelphis albiventris Lund, 1840 to $500 \mathrm{~mm}$ and over $6,000 \mathrm{~g}$ in the largest specimens of Didelphis virginiana Kerr, 1792 (Astúa, 2015, Emmons and Feer 1997, Gardner and Sunquist
2003, Cerqueira and Tribe 2008). The genus also has the largest latitudinal range among all opossums, occurring from $c a .49^{\circ} \mathrm{N}$ in southern Ontario and British Columbia, Canada to $c a .34^{\circ} \mathrm{S}$ in Buenos Aires Province, Argentina. Such variation in latitude, and consequently of habitat types, seasonal variation of temperature, precipitation and resource availability directly influence several aspects of the life history of Didelphis species, such as timing and length of reproductive season (if any), litter size and number of litter per year (e.g. Rademaker and Cerqueira 2006). 
Species of the genus have been the object of several taxonomic and morphometric analyses in the last four decades. Such analyses have usually focused on one or two species occurring within a range, such as those occurring in North America or Venezuela (Gardner 1973, Ventura et al. 2002), have focused in the morphometric variation and diversification within species groups (Cerqueira and Lemos 2000, Lemos and Cerqueira 2002), on allometric relationships within a single species (Abdala et al. 2001, Flores et al. 2003), or included some species with a larger taxonomic sample (Astúa de Moraes et al. 2000). As a results, the genus, that 50 years ago included two species and several subspecies, presently includes six recognized living species (Figure 1): Didelphis virginiana, Didelphis albiventris, $D$. pernigra Allen, 1900, D. imperfecta Mondolfi \& Pérez-Hernández, 1984, D. marsupialis Linnaeus, 1758 and D. aurita (Wied-Neuwied, 1826). Additional studies on the genus have focused on its distribution patterns, or on processes leading to its evolutionary and biological origin (Cerqueira 1985, Lemos et al. 2001, Sebastião and Marroig 2013). However, no study has so far analyzed size and shape variation simultaneously across all currently recognized species of the genus.

This study is part of an ongoing broader study on the evolution of size and shape in New World opossums (Astúa de Moraes et al. 2000, Astúa 2009,2010 ), and focuses specifically in the diversification on size and shape in the cranium and mandible in the living species of Didelphis, using a geometric morphometrics approach.

\section{MATERIAL AND METHODS}

I took digital images of the cranium (in dorsal, ventral, and lateral views) and the mandible with a Nikon Coolpix 995 camera (Nikon, Inc., Melville, New York) at a resolution of $1,280 \times 960$ pixels. Crania and mandibles always were oriented similarly; that is, frontal plane passing through the root of incisors and base of occipital condyle (for dorsal views), palate plane (for ventral views), midsagittal plane (for lateral views), and the plane including coronoid process and horizontal ramus (for the mandible), always parallel to the lens plane. All images included a ruler for scale. All specimens analyzed were adult with fully erupted dentition, following Tyndale-Biscoe \& McKenzie (1976). Although Didelphis is known to continue growing after full eruption of dentition, we avoided as possible particularly old specimens to avoid further sources of variation.

I determined 33 landmarks for the dorsal view of the cranium, 25 for the ventral view, 19 for the lateral view, and 19 for the lateral view of the mandible (Figure 2). Landmarks were digitized using TPSDig (Rohlf 2006). In symmetric views (dorsal and ventral), when a specific landmark was missing on one side of the cranium, I reflected the coordinates from the opposite side along the sagittal axis. Landmarks were defined as follows (numbers refer to landmark numbers in Figure 2, and definitions are presented for one side 


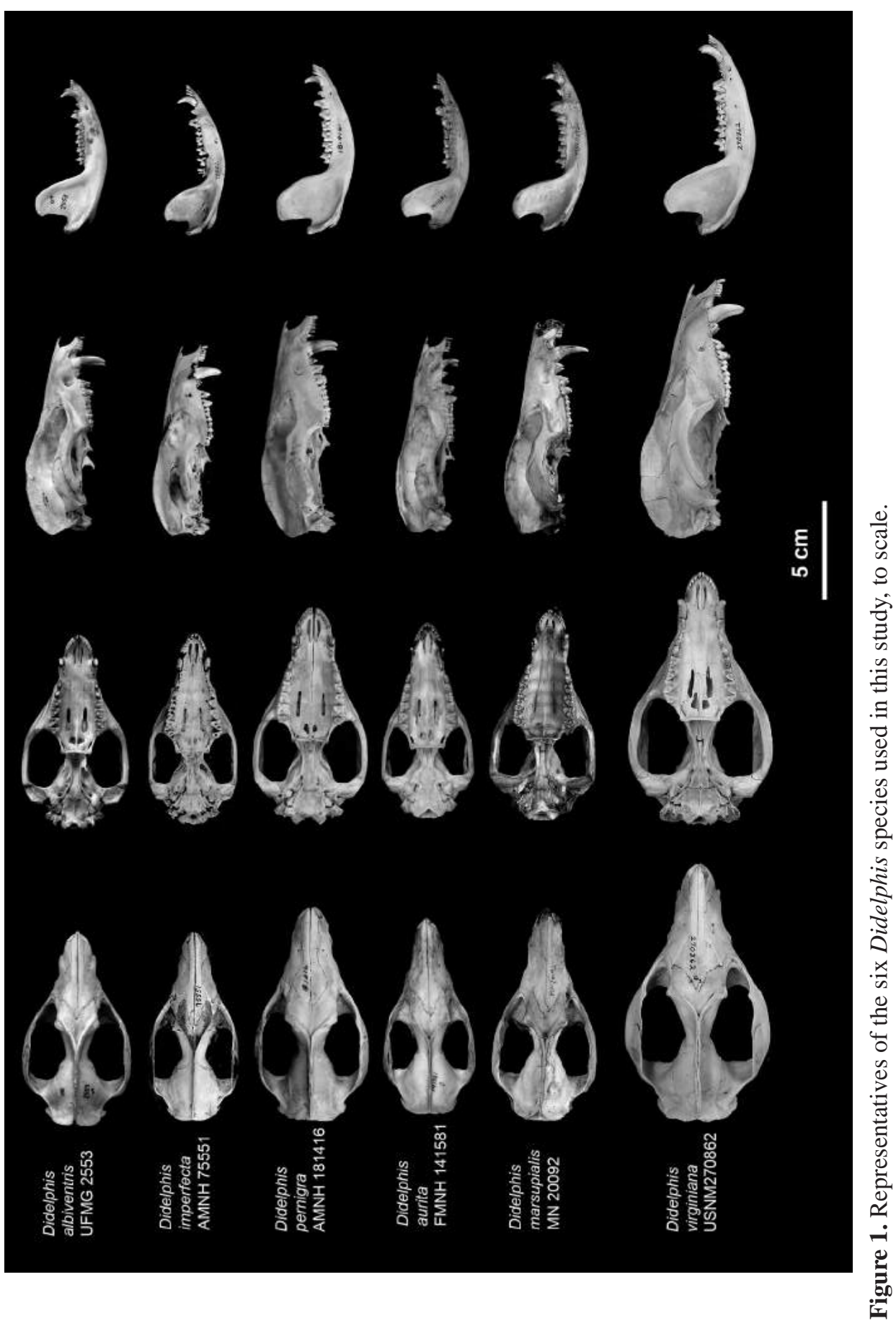




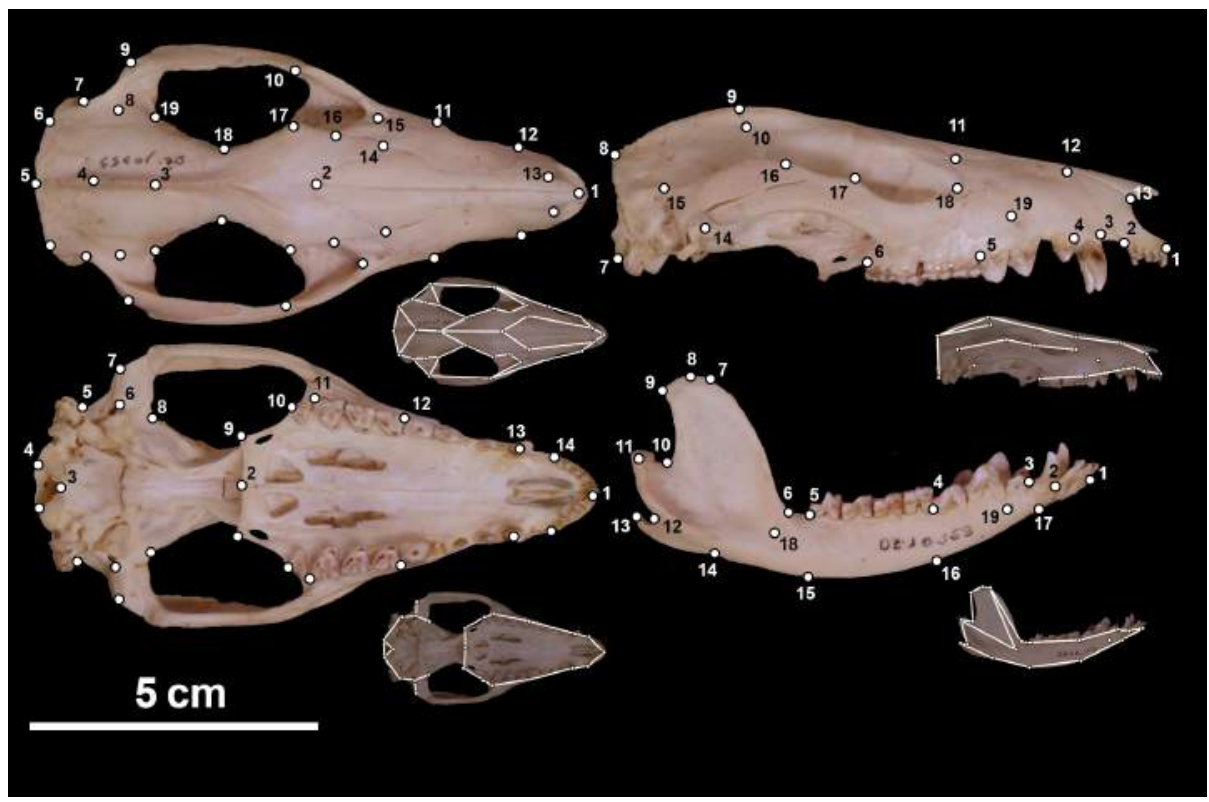

Figure 2. Landmarks used in this analysis, in a skull of Didelphis albiventris. The smaller diagrams represents landmarks linked for better visualization, as used in all subsequent graphs. Refer to the text for the formal definition of landmarks. Landmarks were digitized on both sides but definitions are shown on one side only.

only). I followed Wible (2003) for skull structures nomenclature and Reig et al. (1987) for dental structures.

Dorsal view of the cranium: 1.Anterior end of the suture between right and left nasals, 2.- Posterior end of the suture between right and left nasals, 3.Junction between sutures of right and left frontals and parietals, 4.- Intersection of the sutures between right and left parietals and interparietals, 5.- Posterior end of interparietal, at the intersection of the sagittal line with the nuchal crest, 6.- Intersection of the interparietalparietal sutures with cranium outline, on the nuchal crest, 7.- Inflexion point of squamosal at origin of nuchal crest, anteriorly to the post-tympanic process, 8.- Point of greatest width of braincase,
9.- Point of inflexion (postero-laterally) of zygomatic arch, 10.- Tip of the frontal process of the jugal, on the zygomatic arch, 11.- Inflexion on cranial outline formed by infraorbital foramen, on the maxilla, 12.- Inflexion on cranial outline formed by the root of the canine, on the maxilla, 13.- Anterior end of the suture between the nasal and the premaxilla, 14.- Intersection of the sutures between the nasal, frontal and premaxilla, 15.- Anteriormost point of the orbit, 16.- Point of greater constriction on the frontal, anteriorly to orbital process (inter-orbital constriction), 17.- Tip of orbital process on frontal, 18.- Point of greater constriction the frontal, posteriorly to orbital process (postorbital constriction), 19.- Intersection 
of the anterior border of the zygomatic arch and braincase outline.

Ventral view of the cranium: 1.Located between right and left first upper incisors, 2.- Posterior end of the suture of right and left palatines, 3.- Anteriormost point of foramen magnum, 4.- Posterior tip of right occipital condyle, 5.- Point on the braincase outline anterior to post tympanic process, 6.- Medial tip of postglenoid process, 7.- Lateral tip of postglenoid process, 8.- Base of the anterior border of the alisphenoid portion of the zygomatic arch, 9.Postero-lateral tip of right palatine (right end of the posterior border of the palate), 10.- Posterior stylar cusp (stylar cusp "E" or metastyle) of the fourth right upper molar, 11.- Posterior stylar cusp (stylar cusp "E" or metastyle) of the third right upper molar, 12.- Anterior stylar cusp (stylar cusp "B" or parastyle) of the first right up per molar, 13.- Centre of the alveolus of the right upper canine, 14.- Fifth upper incisor.

Lateral view of the cranium: 1.Anterior base of the first upper incisor, 2.Posterior base of the fifth upper incisor, 3.- Anterior base of the upper canine, 4.- Posterior base of the upper canine, 5.- Base of the upper third premolar and first molar, 6.- Posterior base of the fourth upper molar, 7.- Most postero-ventral point of the occipital condyle, 8.- Most postero-dorsal point of the braincase (posterior end of the sagittal line, at the junction of the nuchal crest), 9.- Dorsal border of the sagittal crest, on the suture of frontal and parietal, 10.- Ventral border of the sagittal crest, on the suture of frontal and parietal, 11.- Intersection of the sutures of the right frontal, nasal and maxilla, 12.- Intersection of the sutures of the right nasal, premaxilla and maxilla, 13.- Anterior end of the suture between the right nasal and premaxilla, 14.- Innermost (postero-dorsally) point of the glenoid cavity, 15.- Posterior end of the zygomatic arch, 16.- Suture between the jugal and squamosal, on the dorsal border of the zygomatic arch, 17.- Tip of the frontal process of the jugal, 18.- Anteriormost point of the orbit, 19.Infraorbital foramen.

Mandible: 1.- Base of first lower incisor, 2.- Posterior base of the fourth lower incisor, 3.- Posterior base of lower canine, 4.- Base of the lower third premolar and first molar, 5.- Posterior base of the fourth lower molar, 6.- Base of the anterior border of the coronoid process (point of greater inflexion and end of horizontal ramus), 7.- Point of greater inflexion (dorsal end) of the anterior border of the coronoid process, 8.- Dorsal most point of the coronoid process, 9.- Posterior end of the coronoid process (top of the posterior border of the coronoid process), 10.Point of greater inflexion of the curve between the mandibular condyle and the posterior border of the coronoid process (base of the posterior border of the coronoid process), 11.- Lateral tip of the mandibular condyle, 12.- Posterior base of the angular process, 13.- Tip of the angular process, 14.- Anterior base of the angular process, 15.- Projection of landmark 5 on the ventral border of the mandible, orthogonal to the line between landmarks 4 and 5, 16.- Projection of landmark 4 on the ventral border of the mandible, orthogonal to the line between landmarks 4 and 5, 17.- Projection of 
landmark 3 on the ventral border of the mandible, orthogonal to the line between landmarks 3 and 4, 18.- Antero-medial end of the masseteric fossa, 19.- Anterior mental foramen.

I tested all landmarks for repeatability. For each view 30 specimens from one species were selected randomly, and all landmarks were digitized twice, randomly reordering the specimens between the two sampling events. I estimated repeatability as the intraclass correlation coefficient, which was derived from an analysis of variance on the $\mathrm{x}$ and $\mathrm{y}$ coordinates of each landmark using individuals as the factor. This took into account intraclass variability (error in locating landmark position) and interclass variation (real differences between individuals) (Falconer 1989). Repeated measurements of the $\mathrm{x}$ and $\mathrm{y}$ coordinates of all landmarks exhibited $<10 \%$ error, and the error rate was $<5 \%$ in $95 \%$ of the cases. All landmarks were considered satisfactory and included in subsequent analyses.

A previous analysis of sexual size and shape dimorphism that included theses specimens revealed the presence of sexual size dimorphism in $D$. albiventris and $D$. aurita only, while sexual shape dimorphism was present in all six species in varying levels, in two, three or all four views and structures tested (Astúa 2010). As the main focus of this analysis is the variation within the genus and differences between species, sexes were pooled for these analyses. Yet, for comparisons purposes, analyses were also run with sexes separately.

Landmark configurations were submitted toaProcrustes superimposition, when centroid sizes (subsequently used as a proxy for cranium and mandible size ) are computed and all information on position, orientation and isometric size of landmark configurations are removed, resulting in sets of aligned or Procrustes coordinates, which contains only shape information unrelated to isometric size.

In order to compare species in size, centroid sizes were submitted to an Analysis of Variance (ANOVA), followed by a Tukey a posteriori test, for all four views. In order to assess levels and patterns of shape variations, Procrustes coordinates were submitted to a Principal Component Analysis, and Procrustes coordinates were regressed onto the PC scores to visualize shape changes associated with each PC. In order to assess differentiation in shape across species, Procrustes coordinates were submitted to a Canonical Variates analysis, and as for the PCA, Procrustes coordinates were regressed onto the $\mathrm{CV}$ scores to visualize shape changes associated with each CV. Although it has been shown that CVA might overfit data and indicate differences even between samples extracted randomly from the same population when number of variables greatly exceed number of specimens (Mitteroecker and Bookstein 2011), I considered this dataset suitable for a CVA (i.e. suitable for a reliable estimate of the variance-covariance structure in the data) as the total sample was larger (2.6x to $4.3 \mathrm{x})$ than $[(2 k-4)$ $+(G-1)]$, where $k$ is the number of variables (i.e. number of landmarks $\mathrm{x}$ 2 ) and $G$ is the number of groups (6, in this case), following Webster and 
Sheets (2010). The same applies for the analyses ran with sexes separately, although in these cases the difference was less marked between total sample (total sample $1.2 \mathrm{x}$ to $2.1 \mathrm{x}$ larger than $[(2 k-4)+(G-1)])$. As a consequence, results from analyses ran by sexes are interpreted more cautiously.

To assess the influence of size on shape variation across species and differentiation between them, scores from the first two PCs and CVs were regressed onto centroid sizes. Additionally, pairwise Procrustes and Mahalanobis distances between species were computed, and the significance of these distances were assessed through permutation tests, with 10,000 permutation rounds. Morphometric analyses were performed on MorphoJ, and regressions on TPSRegr.

\section{RESULTS}

\section{Specimens examined}

A total of 344 specimens were examined. Sample sizes by sex are presented in Table 1. A detailed list of all specimens examined is given in Appendix I.

\section{Size comparisons}

The size of the cranium and the mandible varied significantly across species (Table 2). Results from all three views of the cranium and from the mandible were overall consistent in almost all pairwise comparisons on Tukey tests (Table 3). Didelphis virginiana is significantly larger than all other species, and as a whole, blackeared opossums are larger than whiteeared opossums: D. marsupialis is

Table 1. Total number of specimens of Didelphis used in the analyses, per species, structure, view and sex. Differences in sample sizes between views for a given species are due to the fact that the lack of a needed structure in one particular view leads to a removal of that specimen for that view, although it can still be used onther views. Sample sizes include all specimens (including those with unkown sex, and in parentheses, males and females).

\begin{tabular}{|c|c|c|c|c|}
\hline \multirow[b]{2}{*}{ Species } & \multicolumn{3}{|c|}{ Cranium } & \multirow{2}{*}{$\begin{array}{c}\text { Mandible } \\
\text { n }(\delta / \&)\end{array}$} \\
\hline & $\begin{array}{c}\text { Dorsal view } \\
\text { n }(\lesssim / \&)\end{array}$ & $\begin{array}{c}\text { Ventral view } \\
\text { n }(\hat{\delta} / q)\end{array}$ & $\begin{array}{c}\text { Lateral view } \\
\text { n }(\hat{\jmath} / \uparrow)\end{array}$ & \\
\hline D. albiventris & $60(31 / 29)$ & $60(31 / 29)$ & $60(32 / 28)$ & $60(29 / 31)$ \\
\hline D. aurita & $79(42 / 35)$ & $70(37 / 31)$ & $76(40 / 34)$ & $57(28 / 27)$ \\
\hline D. imperfecta & $16(9 / 7)$ & $16(9 / 7)$ & $16(9 / 7)$ & $16(9 / 7)$ \\
\hline D. marsupialis & $66(26 / 35)$ & $67(27 / 35)$ & $64(26 / 33)$ & $65(27 / 33)$ \\
\hline D. pernigra & $64(27 / 34)$ & $64(26 / 35)$ & $64(27 / 34)$ & $66(27 / 36)$ \\
\hline D. virginiana & $59(30 / 29)$ & $60(29 / 31)$ & $53(27 / 26)$ & $19(3 / 16)$ \\
\hline $\begin{array}{l}\text { Total number of } \\
\text { specimens analyzed }\end{array}$ & $344(165 / 169)$ & $337(159 / 168)$ & $333(161 / 162)$ & $283(123 / 150)$ \\
\hline
\end{tabular}


Table 2. Results of the ANOVA on centroid sizes for each structure and view, for sexes pooled (including specimens with unknown sex) and by sexes separately.

\begin{tabular}{lcccccc}
\hline \multirow{2}{*}{ Structures/view } & \multicolumn{2}{c}{ Sexes pooled } & \multicolumn{2}{c}{ Males } & \multicolumn{2}{c}{ Females } \\
\cline { 2 - 7 } & $\mathbf{F}$ & $\mathbf{p}$ & $\mathbf{F}$ & $\mathbf{p}$ & $\mathbf{F}$ & $\mathbf{p}$ \\
\hline Dorsal view of the cranium & 74.19 & 0.000 & 47.36 & 0.000 & 54.35 & 0.000 \\
Ventral view of the cranium & 91.38 & 0.000 & 56.97 & 0.000 & 61.73 & 0.000 \\
Lateral view of the cranium & 84.53 & 0.000 & 56.97 & 0.000 & 53.17 & 0.000 \\
Mandible & 71.81 & 0.000 & 32.32 & 0.000 & 52.66 & 0.000 \\
\hline
\end{tabular}

Table 3. Results of the Tukey post-hoc tests on centroid sizes between species. Letter indicate significant differences between pairs of species for each view (D: dorsal view of the cranium, V: ventral view of the cranium, L: lateral view of the cranium, M: mandible). Bold face indicates that species in column header is significantly larger, standard face indicates that species in row header is significantly larger. For each pair, the first line refers to sexes pooled (including specimens with unknown sex), second line refers to males and third line to females.

\begin{tabular}{|c|c|c|c|c|c|}
\hline & $\begin{array}{c}D . \\
\text { albiventris }\end{array}$ & $\begin{array}{c}D . \\
\text { aurita }\end{array}$ & $\begin{array}{c}D . \\
\text { imperfecta }\end{array}$ & $\begin{array}{c}D . \\
\text { marsupialis }\end{array}$ & $\begin{array}{c}D . \\
\text { pernigra }\end{array}$ \\
\hline D. aurita & 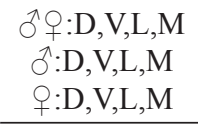 & & & & \\
\hline D. imperfecta & 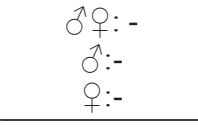 & 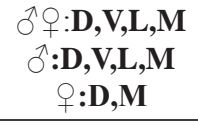 & & & \\
\hline D. marsupialis & 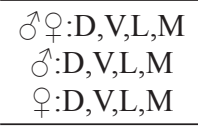 & 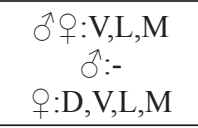 & 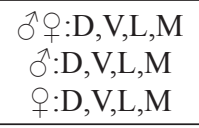 & & \\
\hline D. pernigra & 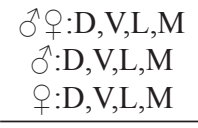 & 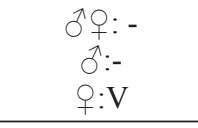 & 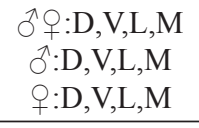 & 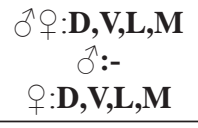 & \\
\hline D. virginiana & 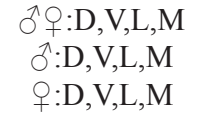 & 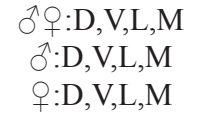 & 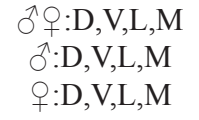 & 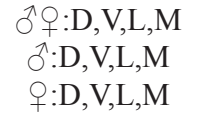 & $\begin{array}{c}\delta^{7}+\mathrm{D}, \mathrm{V}, \mathrm{L}, \mathrm{M} \\
\mathrm{O}: \mathrm{D}, \mathrm{V}, \mathrm{L}, \mathrm{M} \\
\mathrm{q}: \mathrm{D}, \mathrm{V}, \mathrm{L}, \mathrm{M}\end{array}$ \\
\hline
\end{tabular}

larger than all three species of white- fact, this is due to the fact that D. aurita eared opossums (D. albiventris, $D$. is smaller than $D$. marsupialis in most imperfecta and $D$. pernigra), while $D$. views, and that $D$. pernigra is the largest aurita is larger than $D$. albiventris and $D$. of the three white-eared species, while imperfecta, but not than $D$. pernigra. In the remaining two do not differ in size. 
Shape variation

There is a great amount of overlap among the six species on the morphospace defined by the first two PCs, regardless of the view (Figures 3 to 6). These two PCs explain varying amounts of the total shape variation $(40 \%, 62.9 \%, 38.2 \%$ and $43.8 \%$ for the dorsal, ventral and lateral views of the cranium and the mandible, respectively), but the main overlapping pattern is similar or increasing in subsequent PCs (not shown). This means that the major axes of shape variation across species are similar to the main axis of shape variation within species.

For the cranium in dorsal view, the first PC is associated with cranium shapes that are relatively shorter and stouter, with relatively shorter rostra and broader braincases on its negative end, while relatively longer crania with smaller braincases and longer rostra are on its positive end. While there is extensive overlap for most species, D. virginiana overlaps little or very little with the white-eared opossums, particularly $D$. albiventris, with the former having the more elongated and narrower cranium and the latter the shorter and stouter cranium (Figure 3). PC2 is also associated with a progressive shortening of the whole cranium, but associated with a narrower post-orbital constriction and smaller braincase as it increases, but a similar variation pattern is found across all six species that as a consequence overlap almost
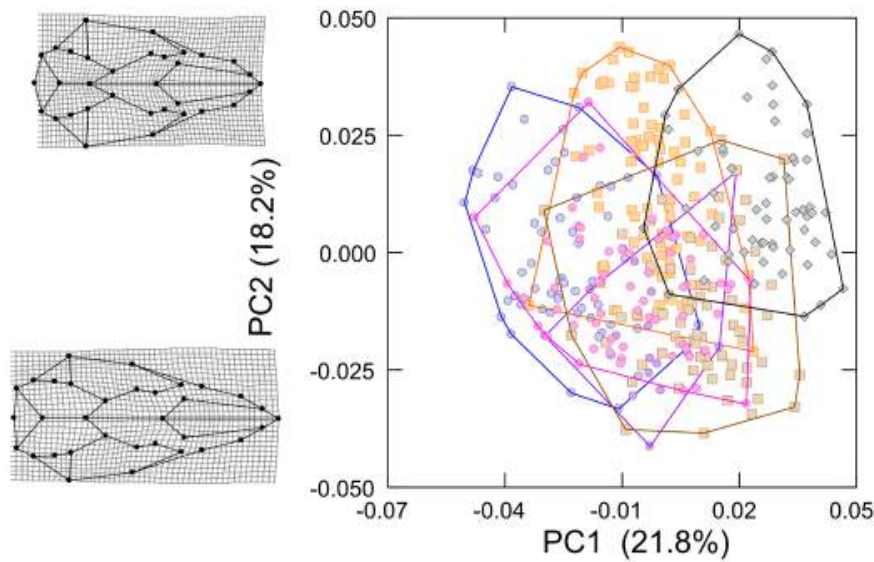

D. albiventris

D. aurita

D. imperfecta

D. marsupialis

D. pernigra

- D. virginiana
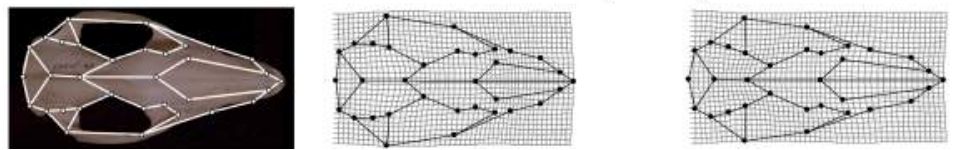

Figure 3. Principal components (PC) analysis of Procrustes coordinates of the landmarks set on the cranium (in dorsal view) of specimens of the six Didelphis species, and percentage of variance explained by the first two PCs. Grids indicate deformations associated with the extremes of each PC axis, from a multivariate regression of Procrustes coordinates onto PC scores. 
completely along this axis. When sexes are compared separately, the overlap is very similar for females, but in males, D. virginiana is completely separated from $D$. marsupialis and D. albiventris (Supplemental Material, Figure I).

For the ventral view of the cranium, all species overlap along the first PC, which is associated, as it increases, with relatively wider post-glenoid processes, and narrower palates with relatively smaller molar rows and a relatively longer post-molar portion of the palate. The second PC, however, along its positive end clearly distinguishes $D$. virginiana, with a relatively smaller and narrower braincase and relatively longer palate, from $D$. albiventris and D. marsupialis, with opposite features, located toward its negative end, while all other species show some level of overlap (Figure 4). A similar pattern appears when sexes are analyzed separately (Supplemental Material, Figure I).

All species overlap along the first two PCs of shape variation of the cranium in lateral view. The first PCs is associated with a decrease of the height of the sagittal crest, a flattening of the zygomatic arch, a caudal displacement of the occipital condyle, and a relatively shorter rostrum, while the second is also associated with an increase of the sagittal crest height, yet coupled with an increase in overall cranium height (Figure 5). The same pattern appears for females treated separately, but not for males.

The first PC of mandible shape variation is associated with a narrower horizontal ramus with relatively longer molar and premolar series, and a relatively smaller and more perpendicular coronoid process, while PC2 is mostly associated with a broader coronoid process with a larger masseteric fossa (Figure 6). As in most views of the cranium, this pattern of shape variation is shared across all six species, and as a consequence they overlap along the first two PCs, the same happening when sexes are treated separately (Supplemental Material, Figure I).

\section{Shape differentiation}

There is a clear separation between some species of Didelphis along the first two Canonical Variates, although not all species are completely separated, depending on the view. Additionally, all Procrustes and Mahalanobis distances between species were significant (Table 4). The variation captured by the first two Canonical Variates is higher than that captured by the first two PCs. The first two CVs explain $79.6 \%, 76.8 \%$, $75.6 \%$ and $66.7 \%$ of the total shape variation for the dorsal, ventral and lateral views of the cranium and the mandible, respectively, and only results for these two first CVs will be presented here. On the dorsal view of the cranium, CV1 completely separates Didelphis virginiana from all other species (Figure 7), for having a narrower cranium and braincase and broader nasals. Along CV2 the three species of whiteeared opossums overlap completely or partially, but the two species of blackeared opossums are almost completely separated, with $D$. aurita presenting a wider cranium and shorter nasals than $D$. marsupialis. This pattern is very similar to the one observed in females (although there is a better separation within white- 

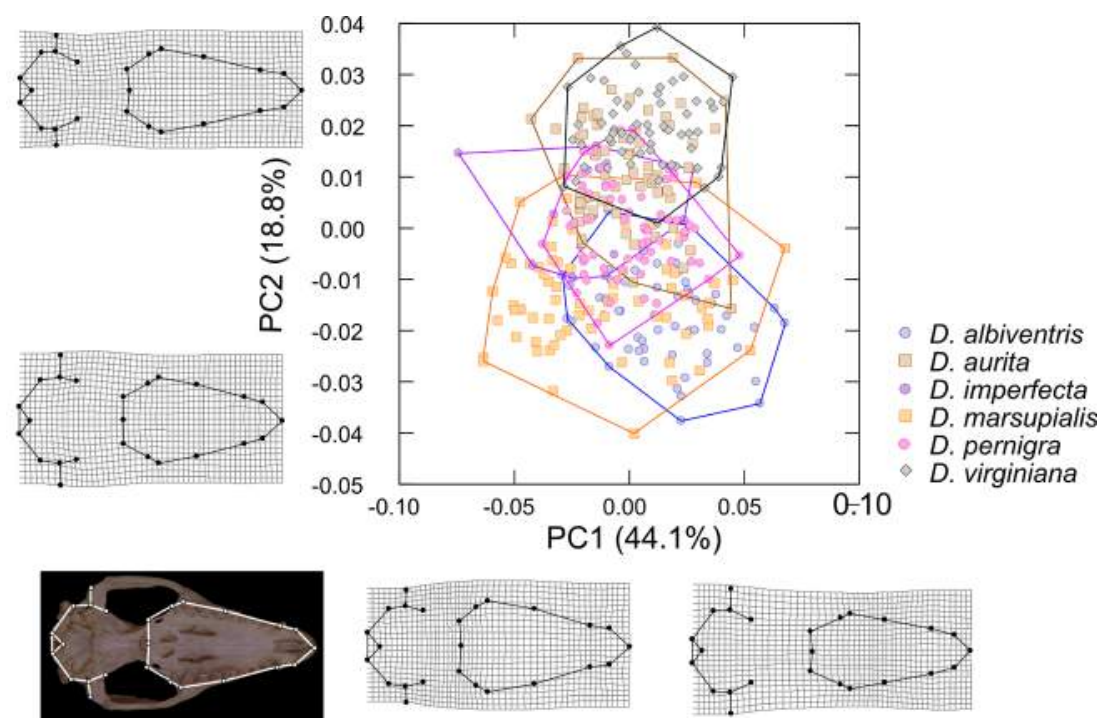

Figure 4. Principal components (PC) analysis of Procrustes coordinates of the landmarks set on the cranium (in ventral view) of specimens of the six Didelphis species, and percentage of variance explained by the first two PCs. Grids indicate deformations associated with the extremes of each PC axis, from a multivariate regression of Procrustes coordinates onto PC scores.
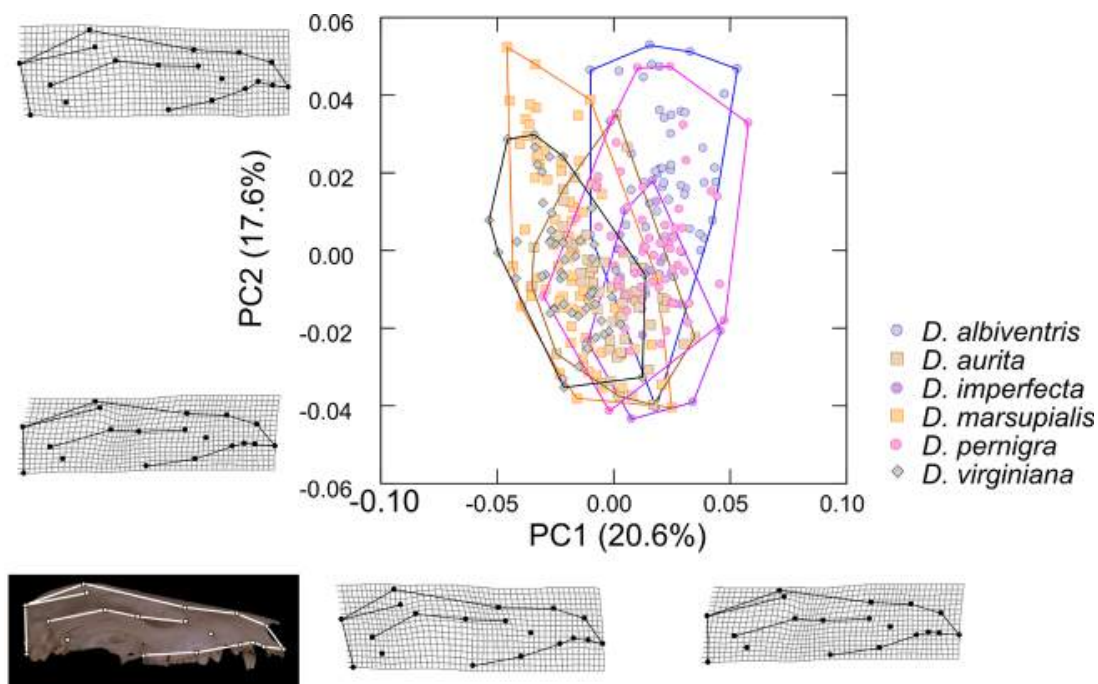

Figure 5. Principal components (PC) analysis of Procrustes coordinates of the landmarks set on the cranium (in lateral view) of specimens of the six Didelphis species, and percentage of variance explained by the first two PCs. Grids indicate deformations associated with the extremes of each PC axis, from a multivariate regression of Procrustes coordinates onto PC scores. 

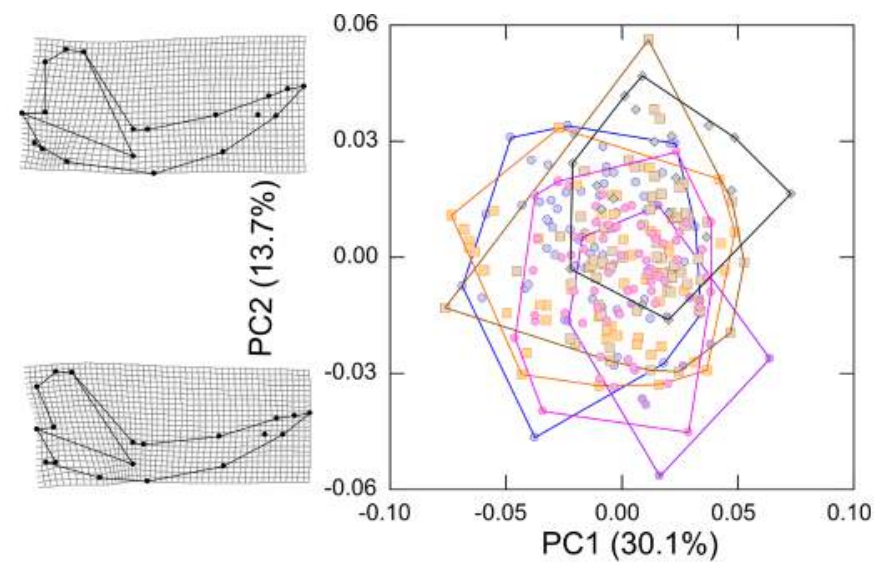

D. albiventris

D. aurita

- D. imperfecta

D. marsupialis

- D. pernigra

D. virginiana
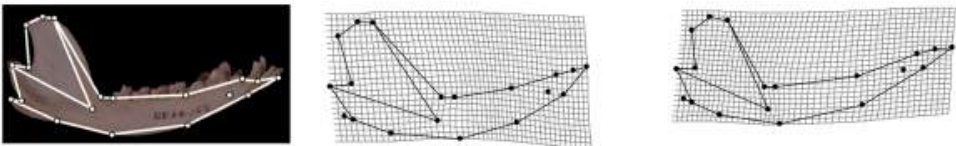

Figure 6. Principal components (PC) analysis of Procrustes coordinates of the landmarks set on the mandible of specimens of the six Didelphis species, and percentage of variance explained by the first two PCs. Grids indicate deformations associated with the extremes of each PC axis, from a multivariate regression of Procrustes coordinates onto PC scores.
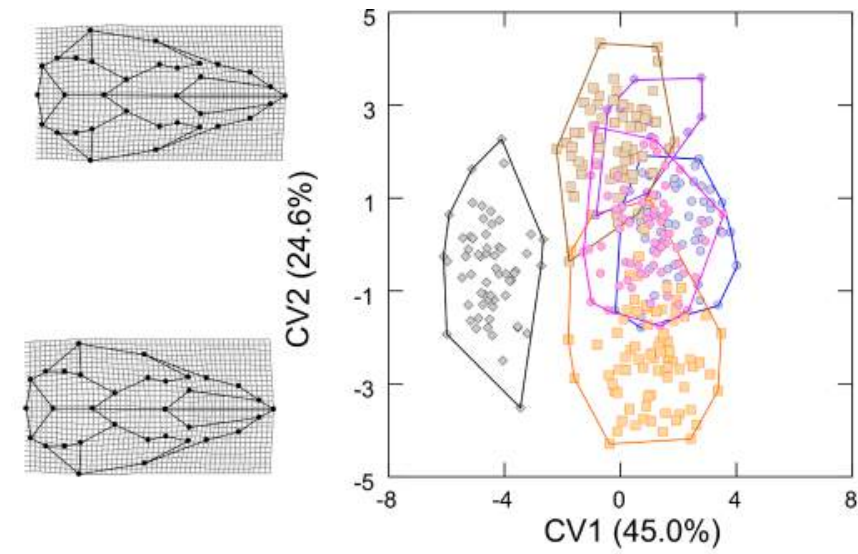

D. albiventris

D. aurita

- D. imperfecta

D. marsupialis

- D. pernigra

- D. virginiana
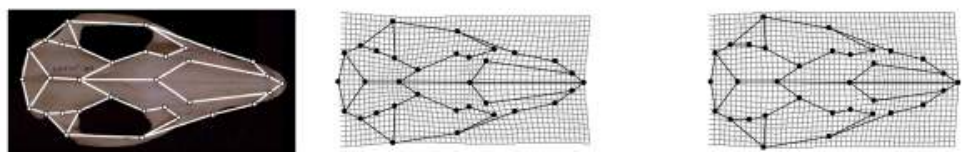

Figure 7. Canonical variates (CV) analysis of Procrustes coordinates of the landmarks set on the cranium (in dorsal view) of specimens of the six Didelphis species (grouped by species), and percentage of variance explained by the first two CVs. Grids indicate deformations associated with the extremes of each $\mathrm{CV}$ axis, from a multivariate regression of Procrustes coordinates onto CV scores. 
eared species), while in males not only $D$. virginiana but also D. marsupialis is completely separated from all other species (Supplemental Material, Figure II). On the ventral view of the cranium the separation of $D$. virginiana from all other species is almost complete (Figure 8), and it presents a longer and narrower palate and a smaller braincase. The second CV also separates partially $D$. aurita and D. marsupialis, although with more peripheral overlap than the dorsal view. When sexes are treated separately, a similar pattern appears for males, with $D$. virginiana completely separated from all other species, and virtually no overlap between the two species of black-eared opossums, while the pattern for females is more similar to the one for sexes pooled (Supplemental Material, Figure II).

Didelphis virginiana is also completely separated on the lateral view of the cranium, with a higher sagittal crest, a longer rostrum and a less ventrally inflected cranium, with the rostrum more dorsally oriented with a greater inflexion at landmark 11 (Figure 9), while CV2 separates almost completely the three whiteeared species from $D$. marsupialis, with the latter a lower sagittal crest and a cranium with a greater ventral inflexion than the former. Along this axis, $D$. aurita appears in an intermediate position, partially overlapping with these two groups. An overall similar pattern appears for sexes treated
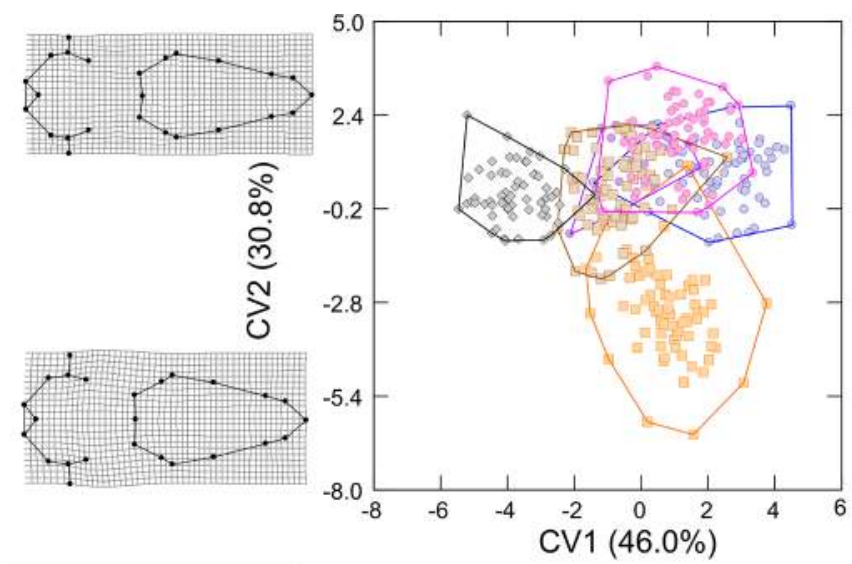

D. albiventris

D. aurita

D. imperfecta

D. marsupialis

D. pernigra

D. virginiana
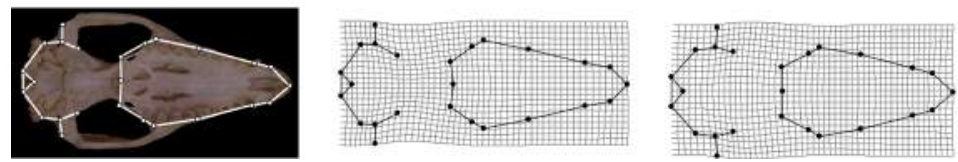

Figure 8. Canonical variates (CV) analysis of Procrustes coordinates of the landmarks set on the cranium (in ventral view) of specimens of the six Didelphis species (grouped by species), and percentage of variance explained by the first two CVs. Grids indicate deformations associated with the extremes of each $\mathrm{CV}$ axis, from a multivariate regression of Procrustes coordinates onto CV scores. 
Table 4. Pairwise Procrustes (above diagonal) and Mahalanobis (below diagonal) distances among all species of Didelphis. For each pair of species, values indicate distances calculated for landmark configurations for the dorsal (D), ventral (V) and lateral (L) views of the cranium and for the mandible (M), respectively. The significance of all distances were assessed through permutation tests, with 10,000 permutation rounds, and all distances presented in this table were significant at $\mathrm{p}<0.005$.

\begin{tabular}{|c|c|c|c|c|c|c|c|}
\hline & & $\begin{array}{c}D . \\
\text { albiven- } \\
\text { tris }\end{array}$ & $\begin{array}{c}D . \\
\text { aurita }\end{array}$ & $\begin{array}{c}D . \\
\text { imper- } \\
\text { fecta }\end{array}$ & $\begin{array}{c}D . \\
\text { marsu- } \\
\text { pialis }\end{array}$ & $\begin{array}{c}D . \\
\text { pernigra }\end{array}$ & $\begin{array}{c}D . \\
\text { virgi- } \\
\text { niana }\end{array}$ \\
\hline \multirow{4}{*}{ D. albiventris } & $\mathrm{D}$ & \multirow{4}{*}{-} & 0.0377 & 0.0307 & 0.0389 & 0.0287 & 0.0535 \\
\hline & $\mathrm{V}$ & & 0.0345 & 0.0360 & 0.0340 & 0.0263 & 0.0410 \\
\hline & $\mathrm{L}$ & & 0.0473 & 0.0355 & 0.0384 & 0.0309 & 0.0552 \\
\hline & M & & 0.0271 & 0.0441 & 0.0295 & 0.0225 & 0.0407 \\
\hline \multirow{4}{*}{ D. aurita } & $\mathrm{D}$ & 4.2078 & \multirow{4}{*}{ - } & 0.0374 & 0.0370 & 0.0293 & 0.0419 \\
\hline & $\mathrm{V}$ & 4.7861 & & 0.0285 & 0.0307 & 0.0301 & 0.0408 \\
\hline & $\mathrm{L}$ & 5.1729 & & 0.0395 & 0.0307 & 0.0404 & 0.0392 \\
\hline & M & 4.4870 & & 0.0428 & 0.0303 & 0.0292 & 0.0417 \\
\hline \multirow{4}{*}{ D. imperfecta } & $\mathrm{D}$ & 4.2884 & 5.2540 & \multirow{4}{*}{-} & 0.0192 & 0.0208 & 0.0451 \\
\hline & V & 3.9166 & 4.9429 & & 0.0192 & 0.0207 & 0.0340 \\
\hline & $\mathrm{L}$ & 4.1760 & 5.4050 & & 0.0286 & 0.0200 & 0.0521 \\
\hline & M & 4.8896 & 4.7873 & & 0.0277 & 0.0278 & 0.0448 \\
\hline \multirow{4}{*}{ D. marsupialis } & $\mathrm{D}$ & 4.4988 & 4.7565 & 3.2248 & \multirow{4}{*}{-} & 0.0255 & 0.0345 \\
\hline & $\mathrm{V}$ & 4.3859 & 4.1228 & 2.6735 & & 0.0175 & 0.0211 \\
\hline & $\mathrm{L}$ & 4.316 & 4.2237 & 3.8067 & & 0.0341 & 0.0348 \\
\hline & M & 4.1478 & 4.0624 & 3.4883 & & 0.0185 & 0.0257 \\
\hline \multirow{4}{*}{ D. pernigra } & $\mathrm{D}$ & 4.0770 & 4.0152 & 4.1271 & 4.0977 & \multirow{4}{*}{ - } & 0.0436 \\
\hline & V & 3.8269 & 4.9859 & 3.4014 & 3.2254 & & 0.0333 \\
\hline & $\mathrm{L}$ & 4.1517 & 5.3052 & 2.9789 & 4.3597 & & 0.0500 \\
\hline & M & 3.3176 & 4.2919 & 3.6729 & 2.8739 & & 0.0351 \\
\hline \multirow{4}{*}{ D. virginiana } & $\mathrm{D}$ & 6.7370 & 6.1120 & 6.6856 & 5.5688 & 6.0147 & \multirow{4}{*}{ - } \\
\hline & V & 6.3772 & 5.7803 & 4.7828 & 3.8562 & 5.6327 & \\
\hline & $\mathrm{L}$ & 7.7664 & 6.8781 & 7.2699 & 5.8687 & 6.6833 & \\
\hline & M & 5.2610 & 5.2465 & 5.4293 & 4.2011 & 4.1061 & \\
\hline
\end{tabular}

separately, with $D$. virginiana and $D$. marsupialis as the most distinctive species, although in males there is also a better discrimination between some white-eared species (Supplemental Material, Figure II). In contrast with the cranium analyses, the mandible shape seems more homogeneous across
Didelphis species, as the CVA could not completely distinguish $D$. virginiana nor any other species, as all species show at list a little overlap. Also in contrast with cranium analyses, the two species that are most clearly distinguished along CV1 are D. albiventris and $D$. marsupialis, with the latter presenting 

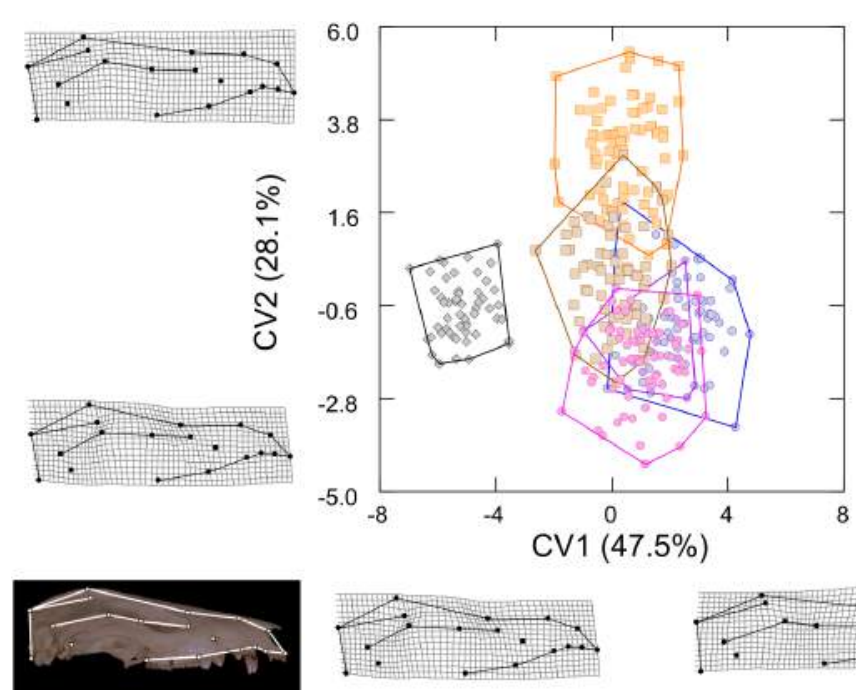

D. albiventris

D. aurita

D. imperfecta

D. marsupialis

D. pernigra

D. virginiana

Figure 9. Canonical variates (CV) analysis of Procrustes coordinates of the landmarks set on the cranium (in lateral view) of specimens of the six Didelphis species (grouped by species), and percentage of variance explained by the first two CVs. Grids indicate deformations associated with the extremes of each $\mathrm{CV}$ axis, from a multivariate regression of Procrustes coordinates onto CV scores.

a narrower coronoid process and a shorter and more dorsally inflected horizontal ramus (Figure 10). Treating species separately resulted in a better discrimination between species, with D. marsupialis and D. albiventris as the most distinctive species in both sexes (Supplemental Material, Figure II).

\section{Effects of size on shape variation and differentiation}

Regressions of PCs and CVs on centroid size showed that allometry plays an important role in shape variation and differentiation across Didelphis species: as a whole, shape variation was significantly correlated with size (at varying intensities) in both $\mathrm{PC} 1$ and $\mathrm{PC} 2$ for all views and structures (Figures 11 and 12). Additionally, CV1, the main axis of shape differentiation between species, was also significantly (and more than PCs) with size for the cranium, while the mandible, that showed less discrimination, showed little, albeit significant, correlation with size (event though CV2 of the mandible was the only CV2 with a slightly larger and significant correlation with size).

PCs showed correlations ranging from $c a$. 0.2 to up to 0.6 (Figure 11) with size. Additionally, scatterplots of PC scores on centroid sizes show that not only shape variation within the genus has a strong allometric effect, but also that allometry strongly influences variation within species. In fact, correlation levels within the genus are probably lower that within species, as in several cases species slopes are parallel to each other, thus reducing the overall correlation coefficient. This 

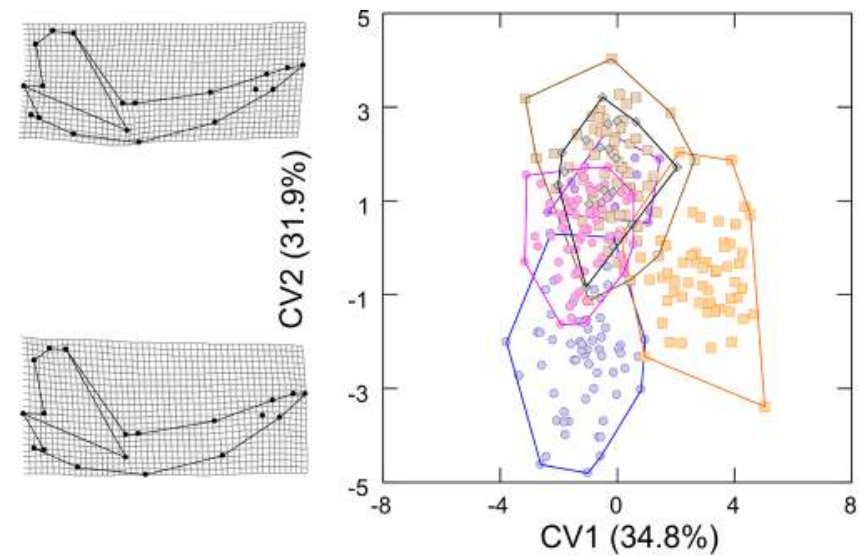

D. albiventris

D. aurita

D. imperfecta

D. marsupialis

D. pernigra

D. virginiana
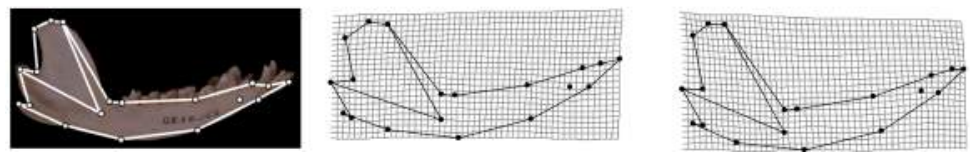

Figure 10. Canonical variates $(\mathrm{CV})$ analysis of Procrustes coordinates of the landmarks set on the mandible of specimens of the six Didelphis species (grouped by species), and percentage of variance explained by the first two CVs. Grids indicate deformations associated with the extremes of each $\mathrm{CV}$ axis, from a multivariate regression of Procrustes coordinates onto CV scores.

shows that size vs. shape allometric trajectories are highly conserved across species and very similar. As both PC1 and PC2 are directly influenced by size and in a similar manner across species, the resulting distribution of species in the PC morphospace is mostly homogeneous and with extensive species overlap, as all species vary in size and shape in a similar manner.

CVs showed a different pattern, with higher correlations between CV1 and centroid size, thus indicating that the main shape differences that distinguish D. virginiana from all other species are allometric. But CV 2, that partially or nearly completely distinguish species pairs, are very little or not correlated with size, indicating that some of the shape features that distinguish these species pairs are purely shape, with no isometric or allometric size influence.

\section{DISCUSSION}

\section{Size comparisons}

Size comparisons are consistent with previous analyses performed on some Didelphis species pairs or groups (Gardner 1973, Mondolfi and PérezHernández 1984, Catzeflis et al. 1997, Cerqueira and Lemos 2000, Lemos and Cerqueira 2002, Ventura et al. 2002), or with available data on species body sizes (Eisenberg 1989, Redford and Eisenberg 1992, Emmons and Feer 1997, Eisenberg and Redford 1999, Rossi et al. 2012). Comparing sexes separately did not alter the results of overall size comparisons (Table 2), 

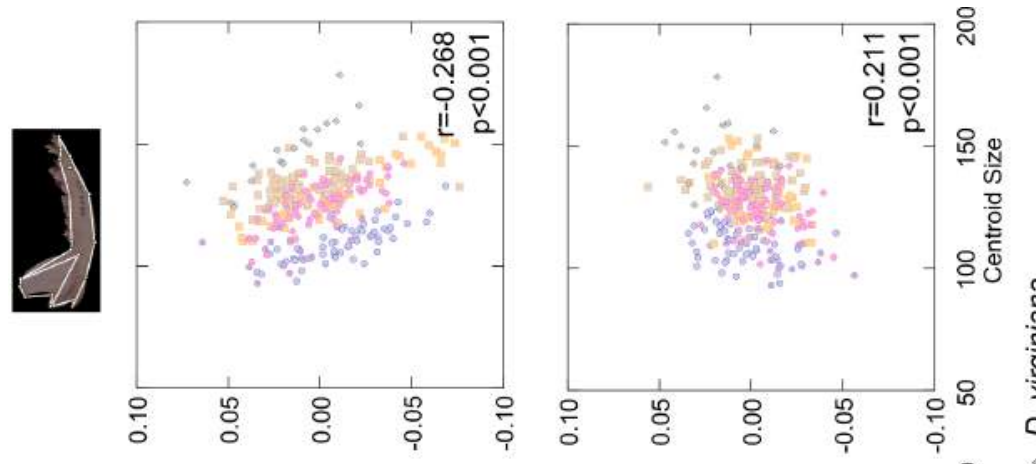

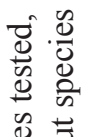
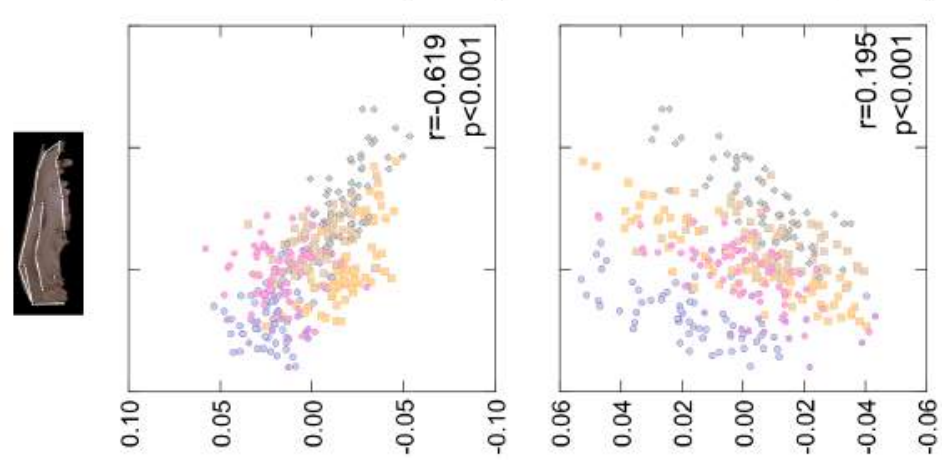

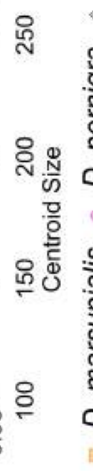
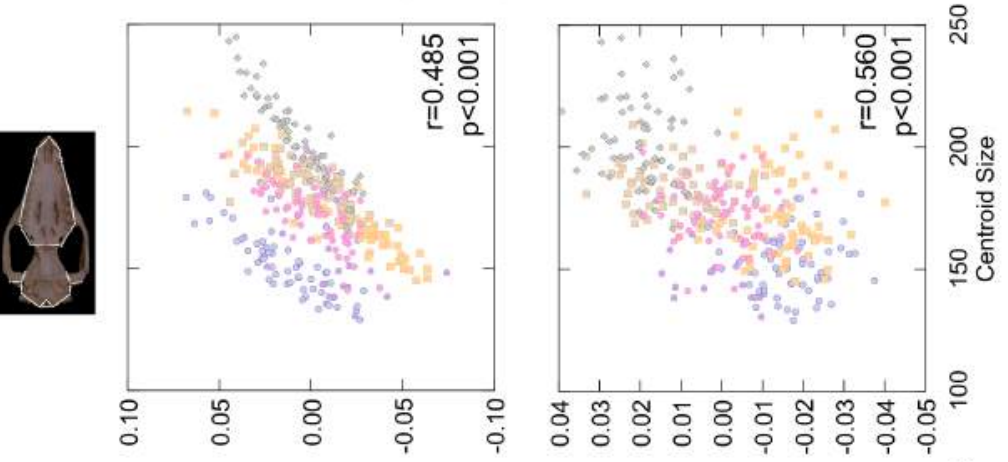

đัँ

을 을

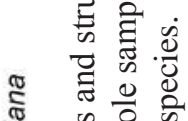

.ิ

.

○.

ज क

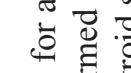

की

क्० के है

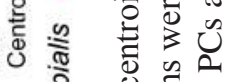

है

范 

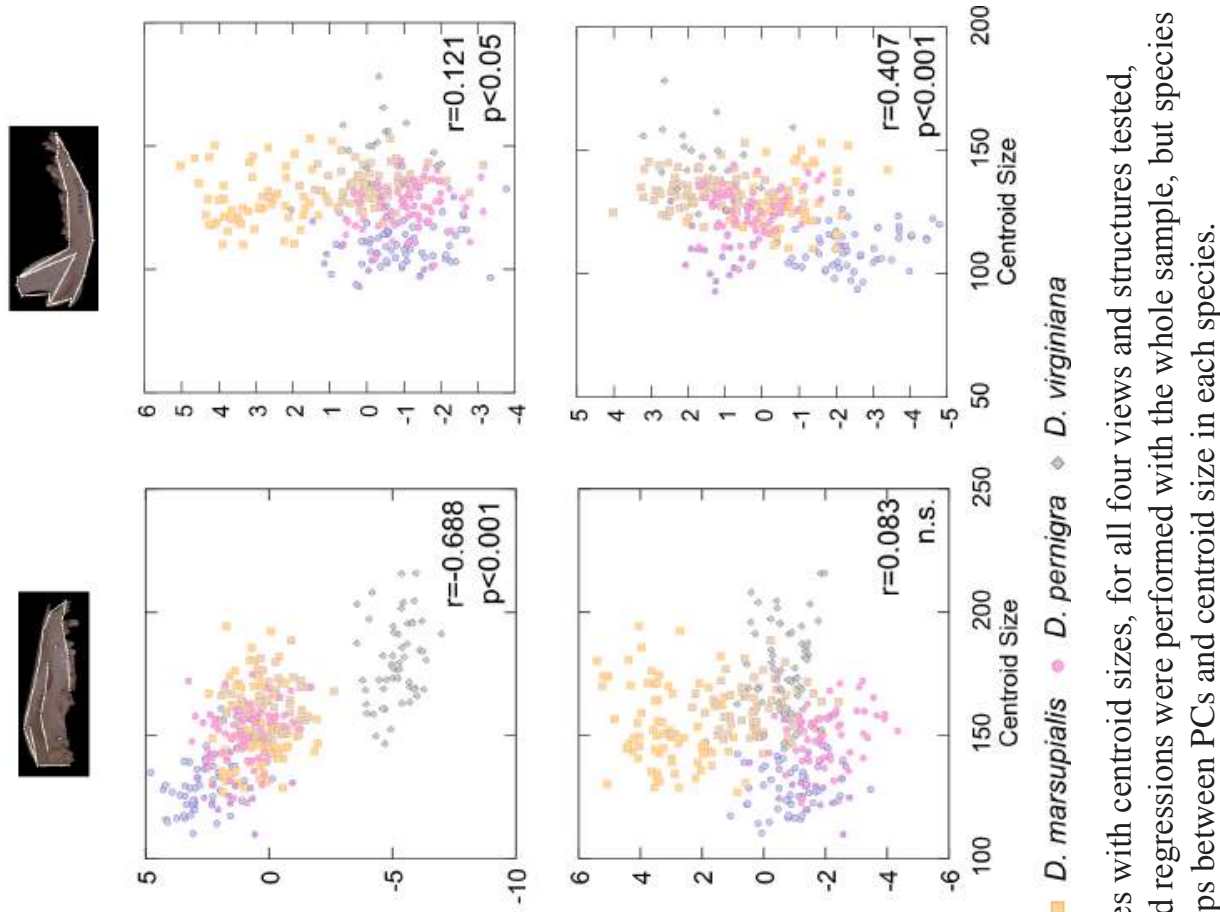

- 言菅. 
although in some cases the results of the pairwise comparisons were different from the analyses with sexes pooled (Table 3).

Didelphis virginiana is the largest species of the genus (Gardner and Sunquist 2003), for males, females, and sexes pooled. This difference in size is related to a faster growth rate in $D$. virginiana, at least compared to $D$. marsupialis (Gardner 1973). Gardner (1973) had also shown that D. virginiana is larger than D. marsupialis. Size differences found here between the two black-eared species are consistent with the analysis of Cerqueira and Lemos (2000), who found that both males and females of $D$. marsupialis are larger than those of $D$. aurita in most cranial linear measurements from a sample of over 1,100 specimens from the whole distribution of the two species. In my smaller sample, however, $D$. marsupialis was found larger than $D$. aurita only for sexes pooled, and for females, while no differences were found for males (Table 3). Those authors also found that, among white-eared species, $D$. pernigra is larger than $D$. albiventris and $D$. imperfecta, while these two species are more similar in size (Lemos and Cerqueira 2002), coinciding with centroid size ANOVA results from this study.

Comparisons between black- and white eared species are, on the other side, less frequent. Catzeflis et al (1997) found that populations of D. marsupialis from French Guyana were significantly larger than sympatric $D$. imperfecta. In the original description of $D$. imperfecta, Mondolfi and Pérez-Hernández (1984) reported a series of body and cranial measurements of $D$. imperfecta, $D$. pernigra and D. marsupialis, in which the first species has smaller measurements than D. pernigra, which in turn is smaller than D. marsupialis, although no significance test results are reported, but Ventura et al. (2002) subsequently statistically confirmed these differences between Venezuelan populations of the three species.

While all of the results from this study agree with most previous analyses (thus confirming that centroid size adequately represents cranial - and possibly body - size), none of these compared all six Didelphis species simultaneously. This analysis not only confirms previous results but provides a full coverage of size variation within the genus: $D$. virginiana is the largest species, blackeared opossums as a whole are larger than white-eared opossums, and within the first species group D. marsupialis is larger than D. aurita, while in the second $D$. pernigra is larger than D. albiventris and D. imperfecta, which do not differ in size. As a consequence of this species ordination, the smallest of the blackeared opossums, D. aurita, does not differ in size with the largest whiteeared, D. pernigra. It should be recalled, however, that this analysis is based on a small sample as compared to the number of specimens of most Didelphis species currently housed in museums.

\section{Shape variation and diversification}

The results of the PCAs and CVAs are quite distinct in one particular point: while there is considerable overlap in PCAs, there is less so in 
CVAs. The Procrustes superimposition removes isometric size information from the coordinates of the landmark configurations. Therefore, the fact that all species overlap along the first two PCS means that after isometric size removal, the remaining shape variation (along its major axis of variation) is similar for all species. However, the remaining information contains shape information that might be allometric. As a result, while the major axes of variation are similar for all species, the remaining information still retains information that allow to separate at least some of the species based on shape.

For all views of the cranium, the most distinctive species is $D$. virginiana, regardless of the view analyzed (Figures 7 to 10). The differences between this and all remaining species drive the first $\mathrm{CV}$ for all analyses of the cranium, and the difference between $D$. virginiana and any other species is greater than between any of the remaining species, as revealed by Procrustes and Mahalanobis distances (Table 4). Didelphis virginiana is the most basal species in the genus (Flores 2009, Voss and Jansa 2009) and thus has diverged from all other species for a longer time. Additionally, $D$. virginiana is also the largest species in the genus, and as a consequence, of all Didelphidae (Emmons and Feer 1997, Gardner and Sunquist 2003, Cerqueira and Tribe 2008). The amount of variation in shape found between this and all other species could thus be related both to its phylogenetic position (due to divergence time that allowed for a greater differentiation) and to its size, as allometric shape variation.
Both explanations cannot be uncoupled, as increase in body size is a distinct feature of the Didelphini, the clade in which the largest opossums are found. Given the distribution of body sizes along the whole family, increased body size can be considered a derived feature of Didelphini. In fact, reconstructions of ancestral size (based on scapula size) of all Didelphidae have shown that the ancestral of the Didelphidae was a small to medium-sized species, and that the increase in body size in Didelphini is unique within the family, with important implication of skeletal structures related to locomotion (Argot 2001, 2002, 2003, Astúa 2009). Not only increased body size is unique in the Didelphini, it is unique in Didelphis within Didelphini, as it is the species that has reached the largest body size. Therefore, increased size (of all traits) is a particular trait of the genus, and the shape changes observed are very likely due only to allometric effects. In fact, most distinctive shape features of the cranium of $D$. virginiana are typical of size related shape changes, as determined by allometric relationships studied in one species of the genus, Didelphis albiventris (Abdala et al. 2001), or in fact to most mammals: a relatively smaller braincase, relatively longer and wider rostrum and palate, a less ventrally arched cranium and an increased sagittal crest. Additionally, CV1 has shown the greatest values of correlation with centroid size (Figure 12). Marsupials have cranial integration patterns very similar to most mammals, but the magnitude of this integration is much higher than in placental mammals 
(Marroig et al. 2009, Porto et al. 2009). This means that cranial regions are highly integrated and covary very closely, and as a consequence, any selection process selecting for increase in any traits results in correlated and integrated increase in the skull as a whole. Therefore the major axes of variation in marsupials, more so than in placental (Marroig and Cheverud 2005), are directly related to size: they will tend to vary much more in size than in shape. As $D$. virginiana represents the first offshoot in the Didelphis tree, it has been evolving independently for a longer time, it has reached latitudes higher than any other living opossum, and has been increasing in size (regardless of the evolutionary forces leading to such increase) more than any other opossum. As a consequence, its shape has also diverged more from all other species, merely as an allometric consequence of its size increase. Curiously, however, the mandible did not follow such a pattern. The reasons for such a difference are still unclear, but other analyses have shown that diet, phylogeny and size have had different influences on the cranium and mandible of the Didelphidae as a whole (Astúa de Moraes 2004).

Among the other species, shape changes are far less marked, but when they occur, major differences occur between the two species of blackeared opossum, D. aurita and D. marsupialis, and such differentiation occurs along CV2. In contrast to CV1, CV2 shows little or no correlation with size (Figure 12). This indicates that differences between these species are less influenced by allometry. This has two consequences on the understanding of morphological diversification in the genus. First, they are not only different in size, as these (Table 2) and previous (Cerqueira and Lemos 2000) results have shown, but they are also different in shape (allometry-free). This provides additional morphological support for the differentiation of these two species, even though discrete diagnostic morphologic characters are not known. Second, not all diversification within the genus is strictly related to size, and shape can evolve at least in some level decoupled from size. This hypothesis is also partially supported by the levels of differentiation observed in white-eared opossums: while there is considerable overlap between the three species in shape space, they can be distinguished in size, at least between $D$. pernigra and the two remaining species. While $D$. pernigra is the largest white-eared opossum (Table 3), its shape overlaps considerably with that of $D$. albiventris and $D$. imperfecta, suggesting that the differences in size within white-eared species are not necessarily coupled with shape changes.

\section{Shape and size differentiation}

The relations between size and shape reveal even more interesting patterns when correlations of size (centroid size) with major axes of shape variation (PCs) or shape differentiation (CVs) are observed. While PCs have slightly lower correlations with size than CV1, it is interesting to observe that $\mathrm{PC} 1$ and PC2 (independent by definition) are both correlated with size at some level, meaning that allometric shape variation 
in the family spans at least the two major axes of shape space. This can be observed in greater detail when relations between size and shape are highlighted in each species. Close observations of the plots indicate that not only PCs are related to size within the family as a whole, but they seem to be even more tightly related within each species, as can be observed by the slopes and dispersion of data within each species. This supports previously estimates of shared allometric relationships within Didelphidae. Within this sample these relationships refer only to static allometry, as only adults have been used, but comparisons of static and ontogenetic allometry between one species of Didelphis and one representative of its sister genus, Philander, have shown that they share cranium growth patterns and rates, and that differences between genera are due mostly to longer growth trajectories in Didelphis (Sebastião and Marroig 2013). These comparisons, based on the analysis of linear distances, have also found that most of the morphological variation between these two genera is due to size, then to isometric change, and finally a smaller amount of allometric changes. Ontogenetic changes are similar between genera of Didelphidae (Abdala et al. 2001, Flores et al. 2003, Flores et al. 2010), and it is thus reasonable to expect that shape and size relationships are similar across species within Didelphis, as can be observed in the very similar slopes of PCs vs Centroid sizes between species.

In conclusion, these results show that a considerable part of the differentiation between species of Didelphis is related to size. This is to be expected across the family, based on our current knowledge of integration patterns in marsupials (Marroig et al. 2009, Porto et al. 2009, Shirai and Marroig 2010, Sebastião and Marroig 2013), and consequently within the genus. This means that size and shape relationships are conserved and similar between species of Didelphis and very probably a similar pattern is to be expected within all other genera of Didelphidae.

\section{ACKNOWLEDGEMENTS}

I am grateful to the following institutions and professionals (curators and collection managers) for access to collections under their care and help during my visits: R. Voss (American Museum of Natural History); B. Patterson and M.Schulenberg (Field Museum of Natural History); A. Gardner, L. Gordon and C. Ludwig (National Museum of Natural History); L.Costa, Y. Leite and B. Andrade (Universidade Federal de Minas Gerais); J. A. Oliveira, L. F. Oliveira, L. Salles and S. Franco (Museu Nacional, Universidade Federal do Rio de Janeiro); M. de Vivo and J.Barros (Museu de Zoologia da Universidade de São Paulo); and V. Pacheco and E.Vivar Pinares (Museo de Historia Natural de la Universidad Nacional de San Marcos). I am also grateful to two anonymous reviewers for comments that improved the quality of this manuscript. This project was initially funded by a doctoral fellowship from Fundação de Amparo à Pesquisa do Estado de São Paulo (00/11444-7), and a Grant-in-Aid of Research from the American Society of Mammalogists. Support from FACEPE and CNPq (through Research Fellowship 306647/2013-3) is also acknowledged. But above all, I am thankful to Dr. Rui Cerqueira for advising me during the early years of my career, and since then, for inspiring the love and fascination for the opossums.

\section{REFERENCES}

Abdala, F., D. A. Flores, and N. P. Giannini. 2001. Postweaning ontogeny of the skull of Didelphis albiventris. Journal of Mammalogy 82:190-200.

Argot, C. 2001. Functional-adaptive anatomy of the forelimb in the Didelphidae, and the 
paleobiology of the Paleocene marsupials Mayulestes ferox and Pucadelphys andinus. Journal of Morphology 247:51-79.

Argot, C. 2002. Functional-adaptive analysis of the hindlimb anatomy of extant marsupials and the paleobiology of the paleocene marsupials Mayulestes ferox and Pucadelphys andinus. Journal of Morphology 253:76-108.

Argot, C. 2003. Functional adaptations of the postcranial skeleton of two miocene borhyaenoids (mammalia, metatheria), Borhyaena and Prothylacinus, from South America. Palaeontology 46:1213-1267.

Astúa, D. 2009. Evolution of scapula size and shape in didelphid marsupials (Didelphimorphia: Didelphidae). Evolution 63:2438-2456.

Astúa, D. 2010. Cranial sexual dimorphism in New World marsupials and a test of Rensch's rule in Didelphidae. Journal of Mammalogy 91:1011-1024.

Astúa D. 2015. Family Didelphidae (Opossums). Pages 70-186 in D. E. Wilson and R. A. Mittermeier, editors. Handbook of the mammals of the world - Volume 5 - Monotremes and marsupials. Lynx Edicions, Barcelona, Spain.

Astúa de Moraes, D. 2004. Evolução morfológica do crânio e elementos pós-cranianos dos marsupiais americanos (Didelphimorphia, Paucituberculata, Microbiotheria). Departamento de Zoologia da Universidade de São Paulo. [In Portuguese]

Astúa de Moraes, D., E. Hingst-Zaher, L. F. Marcus, and R. Cerqueira. 2000. A geometric morphometric analysis of cranial and mandibular shape variation of didelphid marsupials. Hystrix (n.s) 11:115-130.

Catzeflis, F., C. Richard-Hansen, C. FournierChambrillon, A. Lavergne, and J. Vié. 1997. Biométrie, reproduction e sympatrie chez Didelphis marsupialis et D. albiventris en Guyane française (Didelphidae : Marsupialia). Mammalia 61:231-243.

Cerqueira, R. 1985. The distribution of Didelphis in South America (Polyprotodontia, Didelphidae). Journal of Biogeography 12: 135-145.

Cerqueira, R. and B. Lemos. 2000. Morphometric differentiation between Neotropical black-eared opossums, Didelphis marsupialis and D. aurita (Didelphimorphia, Didelphidae). Mammalia 64:319-327.

Cerqueira, R. and C. J. Tribe. 2008. Genus Didelphis Linnaeus, 1758. Pages 17-25 in A. L. Gardner, editor. Mammals of South America. University of Chicago Press, Chicago.

Cozzuol, M. A., F. Goin, M. D. L. Reyes, and A. Ranzi. 2006. The oldest species of Didelphis (Mammalia, Marsupialia, Didelphidae), from the late Miocene of Amazonia. Journal of Mammalogy 87:663-667.

Eisenberg, J. F. 1989. Mammals of the Neotropics. Vol. 1. The Northern Neotropics: Panama, Colombia, Venezuela, Guyana, Suriname, French Guiana. 449p. University of Chicago Press, Chicago.

Eisenberg, J. F. and K. H. Redford. 1999. Mammals of the Neotropics. Vol. 3. The Central Neotropics: Ecuador, Peru, Bolivia, Brazil. 609p. University of Chicago Press, Chicago.

Emmons, L. H. and F. Feer. 1997. Neotropical rainforest mammals: a field guide. $307 \mathrm{p} ., 2^{\text {nd }}$ edition. University of Chicago Press, Chicago.

Falconer, D. S. 1989. Introduction to quantitative genetics. 438p. Longman, Essex, UK.

Flores, D. A. 2009. Phylogenetic analyses of postcranial skeletal morphology in didelphid marsupials. Bulletin of the American Museum of Natural History:1-81.

Flores, D. A., N. P. Giannini, and F. Abdala. 2003. Cranial ontogeny of Lutreolina crassicaudata (Didelphidae): a comparison with Didelphis albiventris. Acta Theriologica 48:1-9.

Flores, D. A., F. Abdala, and N. Giannini. 2010. Cranial ontogeny of Caluromys philander (Didelphidae: Caluromyinae): a qualitative and quantitative approach. Journal of Mammalogy 91:539-550.

Gardner, A. L. 1973. The systematics of the genus Didelphis (Marsupialia: Didelphidae) in North and middle America. Special Publications of The Museum - Texas Tech University 4:4-81.

Gardner, A. L. and M. E. Sunquist. 2003. Didelphis virginiana. Pages 3-29 in G. A. Feldhamer, B. C. Thompson and J. A. Chapman, editors. Wild Mammals of North America: Biology, Management, and Conservation. John Hopkins University Press, Baltimore, Maryland.

Lemos, B. and R. Cerqueira. 2002. Morphological differentiation in the white-eared 
opossum group (Didelphidae: Didelphis). Journal of Mammalogy 83:354-369.

Lemos, B., G. Marroig, and R. Cerqueira. 2001. Evolutionary rates and stabilizing selection in large-bodied opossum skulls (Didelphimorphia: Didelphidae). Journal of Zoology (London) 255:181-189.

Marroig, G. and J. M. Cheverud. 2005. Size as a line of least evolutionary resistance: Diet and adaptive morphological radiation in new world monkeys. Evolution 59:1128-1142.

Marroig, G., L. T. Shirai, F. B. Oliveira, A. Porto, and V. D. Conto. 2009. The evolution of modularity in the mammalian skull II: Evolutionary consequences. Evolutionary Biology 36:136-148.

Mitteroecker, P. and F. Bookstein. 2011. Linear Discrimination, Ordination, and the Visualization of Selection Gradients in Modern Morphometrics. Evolutionary Biology 38:100114.

Mondolfi, E. and R. Pérez-Hernández. 1984. Una nueva subespécie de zarigüeya del grupo Didelphis albiventris (Mammalia-Marsupialia). Acta Cientifica Venezolana 35:407-413.

Porto, A., F. B. Oliveira, L. T. Shirai, V. Conto, and G. Marroig. 2009. The Evolution of Modularity in the Mammalian Skull I: Morphological Integration Patterns and Magnitudes. Evolutionary Biology 36:118-135.

Rademaker, V. and R. Cerqueira. 2006. Variation in the latitudinal reproductive patterns of the genus Didelphis (Didelphimorphia : Didelphidae). Austral Ecology 31:337-342.

Redford, K. H. and J. F. Eisenberg. 1992. Mammals of the Neotropics. Vol. 2. The Southern Cone: Chile, Argentina, Uruguay, Paraguay. 403p. University of Chicago Press, Chicago.

Reig, O. A., J. A. W. Kirsch, and L. G. Marshall. 1987. Systematic relationships of the living and Cenozoic american "opossum-like" marsupials (Suborder Didelphimorphia), with comments on the classification of these and of the Cretaceous and Paleogene New World and European metatherians. Pages 1-89 in M. Archer, editor. Possums and opossums: studies in evolution. Surrey Beatty \& Sons and The Royal Zoological Society of New South Wales, Sydney.

Rohlf, F. J. 2006. TpsDig. Department of Ecology and Evolution, State University of New York at Stony Brook, Stony Brook, NY.

Rossi, R. V., A. P. Carmignotto, M. V. B. Oliveira, C. L. Miranda, and J. J. Cherem. 2012. Diversidade e diagnose de espécies de marsupiais brasileiras. Pages 23-74 in N. C. Cáceres, editor. Os marsupiais do Brasil: biologia, ecologia e conservação. Editora UFMS, Campo Grande, MS.

Sebastião, H. and G. Marroig. 2013. Size and shape in cranial evolution of 2 marsupial genera: Didelphis and Philander (Didelphimorphia, Didelphidae). Journal of Mammalogy 94: 14241437.

Shirai, L. T. and G. Marroig. 2010. Skull Modularity in Neotropical Marsupials and Monkeys: Size Variation and Evolutionary Constraint and Flexibility. Journal of Experimental Zoology Part B-Molecular and Developmental Evolution 314B:663-683.

Tyndale-Biscoe, C. H. and R. B. Mackenzie. 1976. Reproduction in Didelphis marsupialis and $D$. albiventris in Colombia. Journal of Mammalogy 57:249-265.

Ventura, J., M. Salazar, R. Perez-Hernandez, and M. J. López-Fuster. 2002. Morphometrics of the genus Didelphis (Didelphimorphia : Didelphidae) in Venezuela. Journal of Mammalogy 83:1087.

Voss, R. S. and S. A. Jansa. 2009. Phylogenetic relationships and classification of Didelphid marsupials, an extant radiation of New World Metatherian mammals. Bulletin of the American Museum of Natural History:1-177.

Webster, M. and H. D. Sheets. 2010. A practical guide to landmark-based geometric morpho-metrics. Pages 163-188 in J. Alroy and G. Hunt, editors. Quantitative methods in paleobiology. Paleontological Society Short Course.

Wible, J. R. 2003. On the cranial osteology of the short-tailed opossum Monodelphis brevicaudata (Didelphidae, Marsupialia). Annals of the Carnegie Museum 72:1-66. 

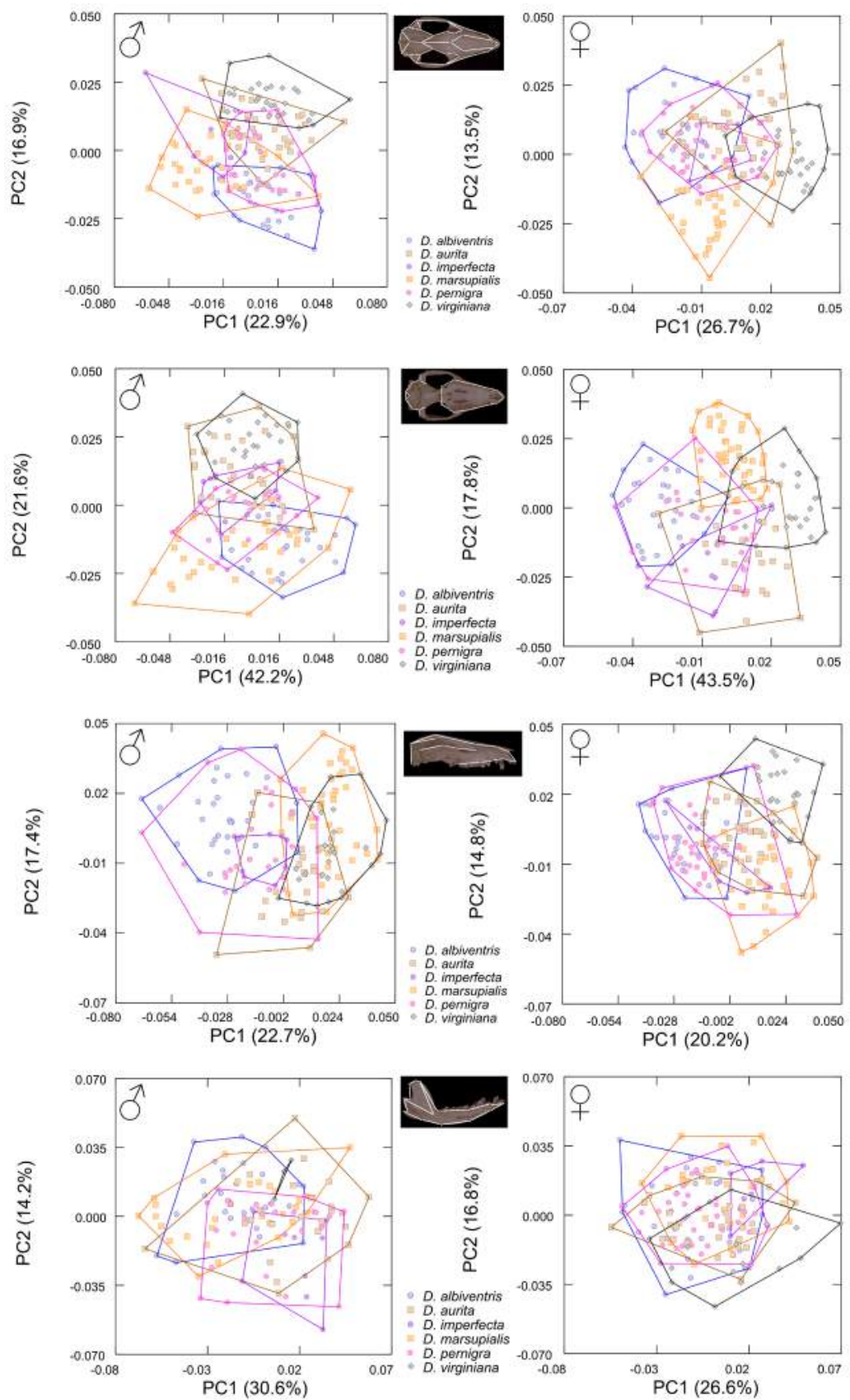

Supplemental Material. Figure I. Principal components (PC) analysis of Procrustes coordinates of the landmarks set on the cranium (in dorsal, ventral and lateral views) and on the mandible of specimens on the six Didelphis species, for males and females separately, and percentage of variance explained the first two PCs. 

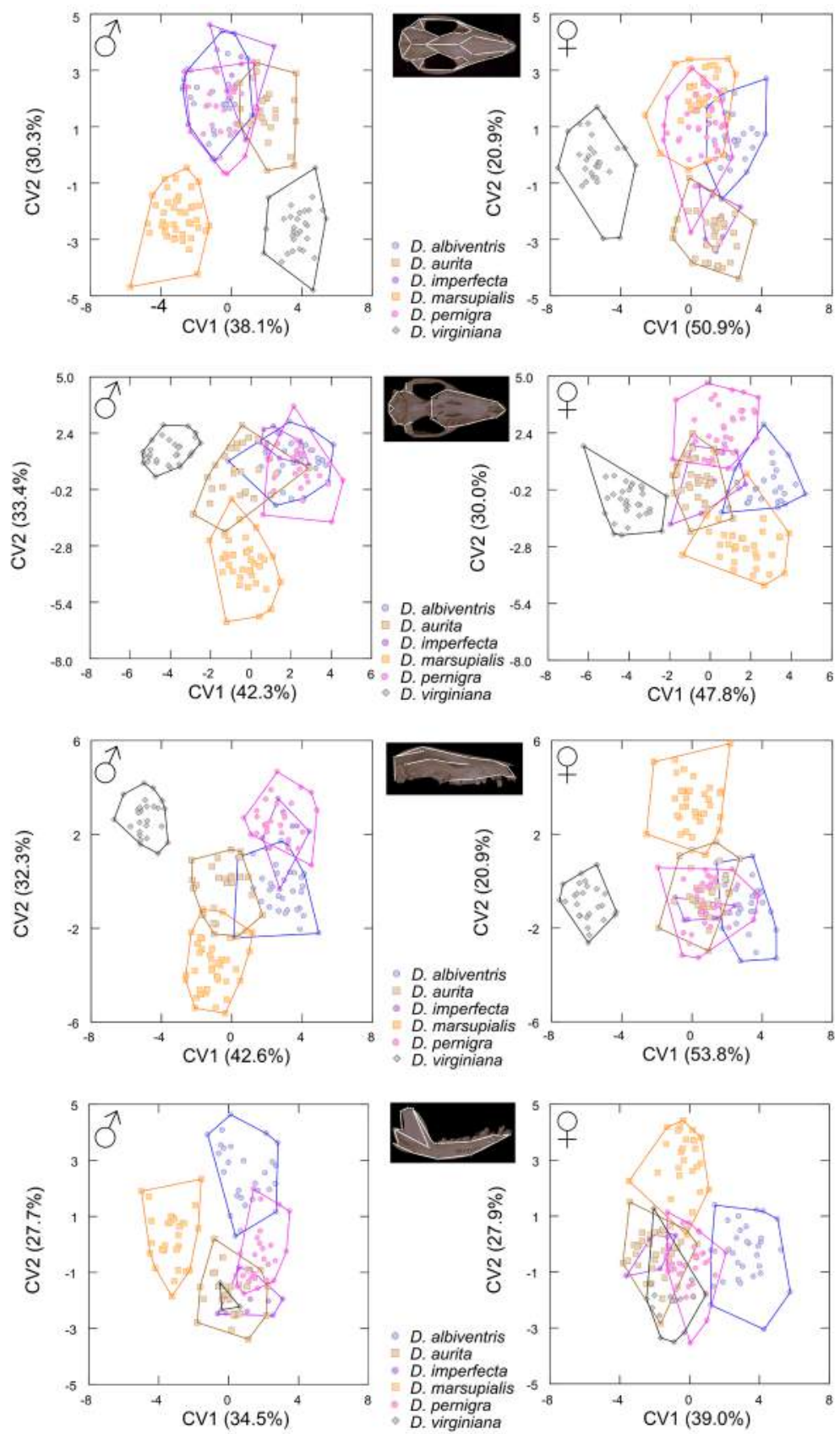

Supplemental Material. Figure II. Canonical variates (CV) analysis of Procrustes coordinates of the landmarks set on the cranium (in dorsal, ventral and lateral views) and on the mandible of specimens on the six Didelphis species, for males and females separately, and percentage of variance explained the first two CVs. 